\title{
Impact of MindUP Among Young Children: Improvements in Behavioral Problems, Adaptive Skills, and Executive Functioning
}

\author{
Claire V. Crooks ${ }^{1}$ (D) $\cdot$ Karen Bax $^{2} \cdot$ Andrea Delaney $^{1} \cdot$ Haesoo Kim $^{1} \cdot$ Mostafa Shokoohi $^{3}$ (i)
}

Published online: 29 July 2020

(C) The Author(s) 2020

\begin{abstract}
Objectives We evaluated the impacts of a mindfulness-based social and emotional learning (SEL) program on behavioral problems, adaptive skills, and executive functioning among kindergarten students.

Methods A total of 23 classrooms were assigned to the intervention group, in which the teachers implemented MindUP, and 19 classrooms were assigned to the comparison group, in which the teachers delivered their classes as usual. Teachers assessed the behavior of students $(N=584$; intervention $n=261$; comparison $n=323)$ both pre- and post-intervention with two measures: the Behavior Assessment System for Children, Third Edition, Teacher Rating Scales (BASC-3 TRS) and the Behavior Rating Inventory of Executive Function-Preschool and Child Version (BRIEF-P; BRIEF-2).

Results Students who received the intervention demonstrated an improvement in adaptive skills and reduction in behavioral symptoms, internalizing composite, and externalizing composite outcomes. Additionally, there was a significant decrease in executive functioning deficits among students who participated in MindUP. There were no gender differences regarding changes in any of the five study outcomes.

Conclusions The study suggests that mindfulness-based SEL intervention can improve psychosocial and behavioral outcomes in young children.
\end{abstract}

Keywords Social and emotional learning $\cdot$ Mindfulness $\cdot$ Schools $\cdot$ Early childhood $\cdot$ Executive function

Schools are increasingly embracing social and emotional programs as an essential part of education (Domitrovich et al. 2017; Greenberg et al. 2017). At the same time, the development of mindfulness-based programming directed at improving child well-being has been increasing in popularity as an educational initiative (Semple et al. 2017). Although these approaches are distinct, they share commonalities and can be seen as highly complementary (Feuerborn and Gueldner 2019). There are a number of school-based programs that

Claire V. Crooks

ccrooks@uwo.ca

1 Centre for School Mental Health, Western University, London, ON, Canada

2 Mary J Wright Research and Education Centre, Western University, London, ON, Canada

3 Division of Social and Behavioural Health Sciences, Dalla Lana School of Public Health, University of Toronto, Toronto, ON, Canada incorporate mindfulness within a social and emotional learning (SEL) framework, and a growing interest in these approaches to student well-being that may not only be complementary, but have added value (Moreno-Gómez and Cejudo 2019; Schonert-Reichl et al. 2015). Below, we provide a brief overview of SEL programming and mindfulness-based approaches used within schools and then discuss these two complementary approaches as background for this research.

Over the past nearly two decades, there has been a growing recognition that to succeed in the twenty-first century, children need to be taught not only academic skills, but also social and emotional skills. Enhancing social and emotional competencies in children through universal programming within classrooms has been a growing area of school-based program development, and in turn, a significant body of evaluation studies (including meta-analyses) has emerged (Durlak et al. 2011; Sklad et al. 2012). The popularity of these approaches likely stems from several factors. First, many can be integrated into the daily teaching practice of educators (Greenberg et al. 2003; Oberle et al. 2016). Therefore, rather than being an addon to classroom instruction, they can be integrated into the 
curriculum. Second, well-implemented programs have been shown to lead to a range of benefits versus single problem behavior targeted programs. Meta-analysis findings revealed that SEL universal programming has a significant positive impact on social and emotional skills, attitudes toward self and others, internalizing and externalizing behaviors, and academic achievement (Durlak et al. 2011). Third, although overall, immediate effects have been found to be stronger than delayed effects, there is evidence that the benefits conferred by these programs can be long-lasting (Taylor et al. 2017).

Mindfulness-informed programs are a more recent addition to school-based programming for children. Despite an explosion in popularity, there are relatively few evaluations, particularly with younger students (Maynard et al. 2017). A systematic review and meta-analysis of school-based programs concluded that such approaches hold promise and may provide benefits in the areas of cognition performance, stress, and resilience (Zenner et al. 2014). The same metaanalysis did not find an overall effect on emotional problems. The authors concluded that the field was still in its infancy and that the variability across studies (i.e., inconsistencies in findings) and small sample sizes precluded clear conclusions. The overall message from Zenner et al. (2014) meta-analysis was a call for larger and more robust intervention studies in this area. In addition, most of the included studies were for children in grades 3 and older, with only one study including students in first grade (Napoli et al. 2005). The study that included younger children found that a 24-week mindfulness intervention program led to benefits in attention among first- to third-grade students (Napoli et al. 2005). Since Zenner et al. (2014) meta-analysis, there has been a growing body of published research, although many of these studies continue to utilize small sample sizes and focus on older children. A subsequent systematic review of mindfulness-based intervention in schools identified only one additional study that extended down to kindergarten-aged students (Felver et al. 2016).

Given the evidence that SEL programming is effective for improving student outcomes, and the growing promise of mindfulness-based interventions in schools to enhance wellbeing, there is interest in the integration of the two approaches from a theoretical standpoint. First, in terms of potential added benefits to further enhance cognitive, educational, social-emotional, and mental well-being of students, and second, from a practical standpoint; educators do not have to choose between two programs when they can be taught and learned together (Maloney et al. 2016). The similar goals across SEL and mindfulness approaches suggest potential compatibility. Within the neuroscience research on mindfulness meditation, enhanced self-regulation has been proposed as the key outcome in mindfulness meditation and thought to constitute three interacting processes: attention control, emotional regulation, and selfawareness (Tang et al. 2015). Feuerborn and Gueldner (2019) elucidated the conceptual fit between mindfulness-based and SEL frameworks by looking at core SEL components of mindfulness-based programs. Self-management, an SEL competency which encompasses self-regulation and executive functioning, was represented in all of the 40 studies that the researchers reviewed. Further, promoting emotional regulation and cultivating compassion and empathy to build healthy relationships are key goals of both mindfulness-based and SEL interventions (de Carvalho et al. 2017).

There are a number of existing school-based programs that incorporate mindfulness and SEL skills, including MindUP, the program being evaluated in this study. Moreno-Gómez and Cejudo (2019) evaluated the effectiveness of a mindfulnessbased SEL program (MindKinder) with kindergarten children and observed a significant reduction in teacher-reported externalizing behavior problems immediately after program implementation and at 6-month follow-up. Short-term neuropsychological effects were found for non-verbal development, visual perception, attention, and overall development. Conversely, enhancement of social skills was not observed until follow-up. Another comparable program (Settle Your Glitter) showed moderate gains in executive functioning in the intervention group (Thierry et al. 2018). Similar to results found in Moreno-Gómez and Cejudo (2019), there were no observed improvements in prosocial behavior. More recently, a small evaluation of the OpenMind-Korea program with preschool children $(n=83)$ found that children participating in the program had better emotion regulation, resilience, and prosocial behavior, compared to children receiving the usual curriculum (Kim et al. 2020).

Schonert-Reichl and Lawlor (2010) investigated the MindUP program and observed improvements in social and emotional competence and behavioral regulation. SchonertReichl et al. (2015) further explored the effects of MindUP with students in grades 4 and 5 by incorporating executive function tasks. Students who received the intervention had lower response times with equal accuracy relative to students who were not exposed to the intervention (i.e., comparison group). The superior performance of MindUP participants suggested an increase in ability to maintain focus, use working memory, and inhibit environmental distractions while performing tasks. Thierry and colleagues also evaluated the influence of MindUP on preschoolers' executive functioning by utilizing a teacher-report questionnaire rather than performance-based tasks (Thierry et al. 2016). The researchers found that students who received the intervention showed greater executive functioning compared to students in the comparison group. Another study on MindUP showed that children in third and fourth grades who participated in the program scored higher on emotional regulation, experienced more positive affect, and displayed more self-compassion when compared with the comparison group (de Carvalho et al. 2017). 
Thus, while the evidence base for MindUP has been growing, there has been little research focusing on students in kindergarten, despite the importance of this stage in the maturation of cognitive functions, including self-regulation and executive functioning (Montroy et al. 2016). The preschool and early school-age years are considered a critical stage of growth in self-regulation, with children typically moving from being more reactive and coregulated to acquiring more advanced self-regulation. However, differences in the development of self-regulation across early childhood can vary widely. The predictive implications for children that struggle with the development of such skills have been consistently related to poor short- and long-term outcomes such as school readiness, selfworth, academic achievement, ability to cope with stress, substance abuse, and law-breaking (McClelland et al. 2013; Montroy et al. 2016). Kindergarten is an important transition year for young students. The demands on students in first grade shift dramatically, and students require the selfregulatory capacity to undertake more teacher-directed work and spend more time in their seats (La Paro et al. 2006). Therefore, the evaluation of kindergarten programs that target the development of self-regulation through social-emotional learning and mindful awareness is critical for their potential impact on the lives of children.

The purpose of this study was to evaluate MindUP among kindergarten children with respect to impacts on behavioral symptoms, adaptive skills, and executive functioning. This study extends current research by focusing on this important transitional period in development. It was hypothesized that students in MindUP classrooms would show improvements in behavior, executive functioning, and adaptive functioning relative to their comparison group peers. We did not have specific hypotheses about gender effects, as these analyses were more exploratory in nature.

\section{Method}

\section{Participants}

All schools were located in a Catholic school district in Southwestern Ontario. The school board with whom we partnered selected schools based on a number of factors including high Social Risk Index (SRI) scores, equity of services, commitment to other ongoing research studies, and school administration interest in supporting mindfulnessbased curriculum. The school board measures Social Risk Index based on the following indicators: parental education, employment, income, government-subsidized incomes, family structure, mobility, language, and immigration. High SRI scores represent higher risk due to a greater presence of disadvantageous characteristics (e.g., unemployment, low income, and lone-parent).
During the 2016-2017 school year, 15 kindergarten classrooms in eight schools were invited to participate in a pilot of the MindUP program and research methods. Kindergarten classrooms in this jurisdiction consist of both junior and senior kindergarten students (i.e., students start kindergarten the year they turn four, and have 2 years of kindergarten programming). Based on the success of the pilot, additional classrooms were added the following year at the same time that comparison classrooms were added to create a quasi-experimental research design. During the 2017-2018 school year (from which data are drawn for this study), the district recruited two additional schools to participate in the intervention condition and seven schools to serve as comparison schools. In the seven comparison schools, 19 kindergarten classrooms participated in the study. In the 10 intervention schools, 23 kindergarten classrooms participated in the study. Although the children from the pilot continued to be part of our data collection procedures, they were excluded from these analyses because some of them were older than the comparison group (i.e., we had intervention children in grade 1 but no grade 1 comparison classrooms) and because we did not want to include children who were participating in the intervention for the second time. This recruitment resulted in intervention and comparison groups of 584 students (intervention $n=261$; comparison $n=323$ ). Figure 1 provides an overview of the study design and sample size.

\section{Procedure}

This study was approved by the Western University's NonMedical Research Ethics Board. Educators in the invited schools sent home letters of information with all students in their classrooms and obtained written parental consent for children to participate. All children in the classes were eligible to participate. Educators were compensated to complete ratings based on the observed behaviors of the student participants at two time points: T1 (September-December 2017; preimplementation) and T2 (May-June 2018; post-implementation). Educators completed the measures through an online, secure surveying software.

Intervention The intervention was a mindfulness-based SEL curriculum (MindUP) implemented by trained teachers and early childhood educators over the course of a school year. The Hawn Foundation trained the educators in MindUP with a full day training at the beginning of the school year and a full day extension training partway through the school year. The program start date varied, as the educators were required to complete the pre-implementation measures prior to starting the program. The dosage (i.e., amount of time) and duration (i.e., number of weeks across which the educator implemented activities) of the intervention depended on the individual educators, consistent with a realist evaluation framework 


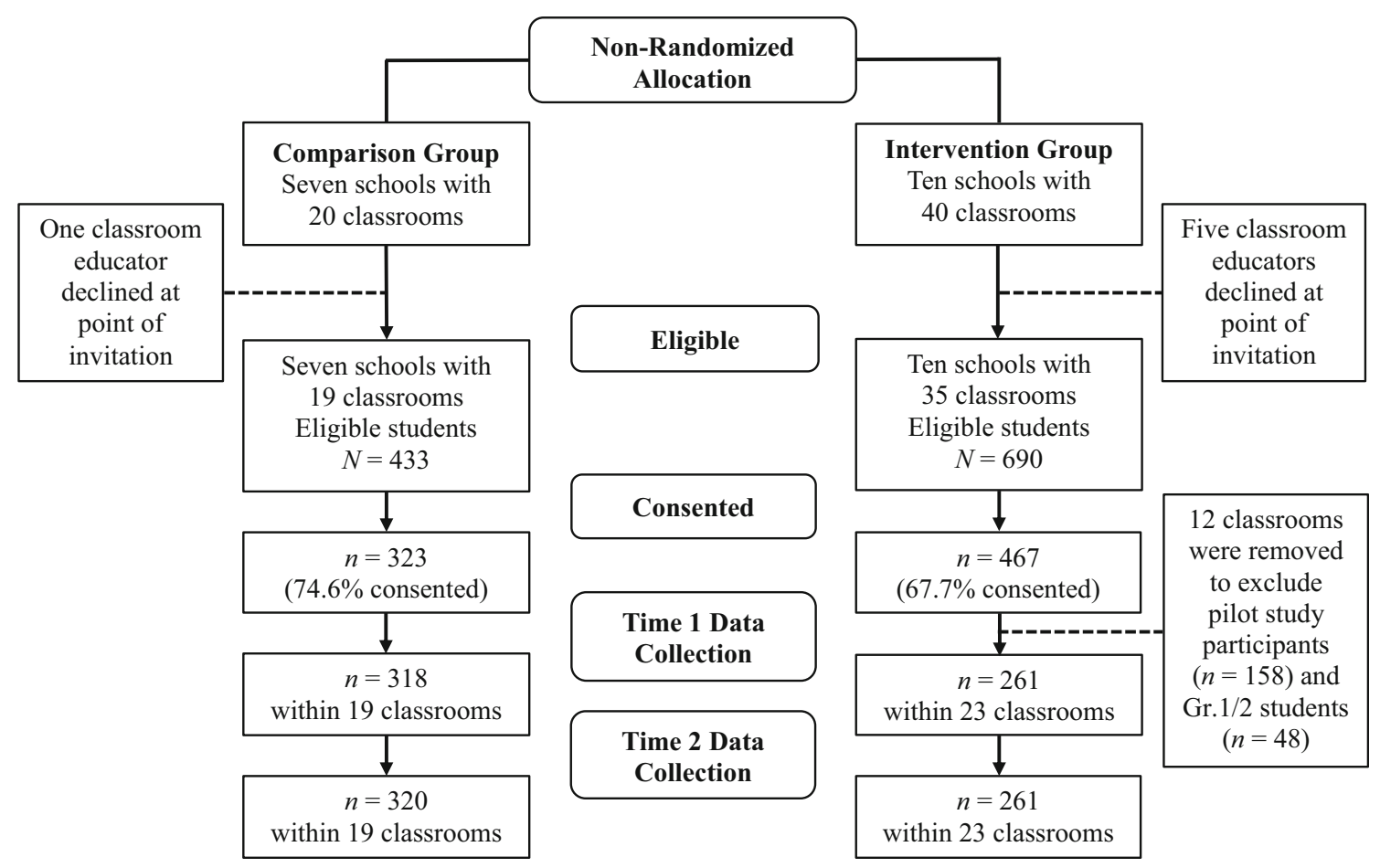

Fig. 1 Study design including the number of schools and students in each condition

(Bonell et al. 2011). To assess implementation fidelity, educators completed lesson tracking sheets, in which they indicated the completion date, the total time spent, and completed curricular components (e.g., journal writing and literature links) for each lesson.

The MindUP program is one of the most widely studied school-based programs to date and is the focus of this research. MindUP is a manualized program informed by cognitive developmental neuroscience, contemplative science and mindful awareness, positive psychology, and SEL. The MindUP curriculum includes activities that promote mindful awareness and the five SEL competencies: self-awareness, self-management, social awareness, relationship skills, and responsible decision-making. The curriculum consists of 15 sequential lessons taught approximately once per week in 1015 min chunks. The four domains and session topics are shown in Table 1. There are several extension activities that connect with curriculum expectations, including science, math, language arts, and SEL. There are four units: Getting Focused (introduction to brain structure and function, the core practice, and how focused awareness affects the brain and feelings), Sharpening Your Senses (focus on internal experiences such as mindful smelling and tasting), It's All About Attitude (focus on cognitive experiences such as positive mindset, perspective taking, and practising gratitude), and Taking Action Mindfully (performing acts of kindness to others and building positive relationships). An essential component of the program is the core practice, a focused breathing exercise, and mindfulness practice that is recommended to be implemented three times per day for one or more minutes at a time. The core practice and components of the program are intended to promote cognitive control, engagement with the prefrontal cortex, regulation of behavior, regulation of stress, well-being, and prosociality (Maloney et al. 2016).

The educators received the MindUP curriculum manual designed for grades kindergarten to grade 2, a chime for mindful awareness practice, and other materials to promote the successful implementation of MindUP (i.e., storybooks, Hoberman sphere, and card deck of mindfulness games). The training and resources were provided to the educators upon their commitment to implement MindUP. Educators in both the MindUP and comparison conditions were engaged as paid research assistants. The research assistant role involved distributing and collecting informed parental consent forms and completing two measures for participating children at two data collection time points per school year: before and after implementing the MindUP curriculum.

Regular Curriculum Comparison school educators did not participate in the MindUP training, or receive MindUP curriculum and resources. Educators implemented their usual teaching practices to meet the expectations of the early childhood curriculum. The regular kindergarten program includes religious education and areas of learning such as Belonging and Contributing and Self-Regulation and Well-being, which focus on gratitude, compassion, self-understanding, social awareness, and emotion-regulation. 
Table 1 MindUP curriculum: units, themes, lessons, and objectives

\begin{tabular}{|c|c|c|}
\hline Unit/theme & Lesson & Objectives \\
\hline \multirow[t]{3}{*}{ Getting Focused (Neuroscience) } & 1: How Our Brains Work & Describe the functions of the amygdala, hippocampus, and prefrontal cortex. \\
\hline & 2: Mindfulness Awareness & Identify the differences between mindful and unmindful behavior. \\
\hline & $\begin{array}{l}\text { 3: Focused Awareness: The } \\
\text { Core Practice }\end{array}$ & $\begin{array}{l}\text { Learn how to perform the core practice: a breathing exercise to calm and focus } \\
\text { the mind. }\end{array}$ \\
\hline \multirow[t]{6}{*}{$\begin{array}{l}\text { Sharpening Your Senses (Mindful } \\
\text { Awareness) }\end{array}$} & 4: Mindful Listening & $\begin{array}{l}\text { Focus on specific sounds to heighten sensory awareness. } \\
\text { Learn how mindful listening skills can enhance communication skills. }\end{array}$ \\
\hline & 5: Mindful Seeing & $\begin{array}{l}\text { Focus on an object and describe what is observed. } \\
\text { Strengthen visual memory. }\end{array}$ \\
\hline & 6: Mindful Smelling & $\begin{array}{l}\text { Focus attention through the sense of smell and identify any thoughts and } \\
\text { feelings triggered by certain smells. }\end{array}$ \\
\hline & 7: Mindful Tasting & $\begin{array}{l}\text { Focus on savoring a snack and describe the experience. } \\
\text { Identify ways that mindful tasting can help develop healthy eating habits. }\end{array}$ \\
\hline & 8: Mindful Movement I & Focus on physical sensations after relaxation and physical exertion. \\
\hline & 9: Mindful Movement II & $\begin{array}{l}\text { Participate in balancing activities to focus the mind. } \\
\text { Connect mindful balancing to living a well-balanced life. }\end{array}$ \\
\hline \multirow[t]{3}{*}{$\begin{array}{l}\text { It's All About Attitude (Positive } \\
\text { Psychology) }\end{array}$} & 10: Perspective Taking & $\begin{array}{l}\text { Identify perspectives of multiple characters in a story. } \\
\text { Consider viewpoints of others in social situations. }\end{array}$ \\
\hline & 11: Choosing Optimism & $\begin{array}{l}\text { Define and describe the differences between optimism and pessimism. } \\
\text { Practise strategies to cultivate optimism. }\end{array}$ \\
\hline & $\begin{array}{l}\text { 12: Appreciating Happy } \\
\text { Experiences }\end{array}$ & $\begin{array}{l}\text { Visualize a pleasurable experience and describe thoughts and feelings that are } \\
\text { associated with the experience. } \\
\text { Learn to appreciate happy experiences to help alleviate negative emotions. }\end{array}$ \\
\hline \multirow{3}{*}{$\begin{array}{l}\text { Taking Action Mindfully (Social \& } \\
\text { Emotional Learning) }\end{array}$} & 13: Expressing Gratitude & Learn the importance of gratitude and practise expressing gratitude. \\
\hline & $\begin{array}{l}\text { 14: Performing Acts of } \\
\text { Kindness }\end{array}$ & $\begin{array}{l}\text { Identify opportunities to perform acts of kindness and explore the benefits of } \\
\text { practising kindness. }\end{array}$ \\
\hline & $\begin{array}{l}\text { 15: Taking Mindful Action in } \\
\text { the World }\end{array}$ & Perform an act of kindness for the school or community. \\
\hline
\end{tabular}

\section{Measures}

As research assistants, teachers rated the students in their classes using the Behavior Assessment System for Children, Third Edition, Teacher Rating Scales (BASC-3 TRS; Reynolds and Kamphaus 2015). The BASC-3 TRS provides clinical ratings of adaptive and maladaptive behavior for children aged 2-5 (Preschool Version) and aged 6-11 (Child Version). The BASC-3 first asks for some basic child demographics (e.g., grade, age, gender, and birth date) and for the teachers to indicate how long they have known the child they are rating. Then, the teachers complete the behavior items (Preschool-105 items; Child-165 items) using a fourpoint scale $(0=$ never, $1=$ sometimes, 2 =often, 3 =almost always) by the frequency they observed the child exhibit the behavior over the past several months. We utilized the BASC3 Behavioral Symptoms Index (BSI; Cronbach's $\alpha$ for Preschool and Child versions in the current study was 0.97 for both versions), the Internalizing Problems (Cronbach's $\alpha$ for Preschool and Child versions was 0.91 and 0.96, respectively) and Externalizing Problems (Cronbach's $\alpha$ for Preschool and Child versions was 0.95 and 0.97 , respectively) composite scales, and the Adaptive Skills composite scale
(Cronbach's $\alpha$ for Preschool and Child versions was 0.94 and 0.96, respectively). The Internalizing and Externalizing Problems composite scales were chosen because research suggests boys are more likely to show externalizing behavior problems, and girls are more likely to display internalizing behavior problems (Maguire et al. 2016). The BSI measures the overall level of behavioral problems and consists of Hyperactivity, Aggression, Depression, Attention, Atypicality, and Withdrawal scales. The Internalizing Problems composite scale includes Anxiety, Depression, and Somatization scales. The Externalizing Problem composite scale includes Hyperactivity, Aggression, and Conduct Problems scales (on the TRS-Child Version only). Higher scores represent higher levels of maladaptive behaviors for the BSI and Internalizing and Externalizing Problems composite scales. Higher scores on the Adaptive Skills composite represent higher levels of prosocial and desirable behavior. The scales on the Adaptive Skills composite include Adaptability, Functional Communication, Social Skills, and Study Skills (on the TRS-Child Version only).

Teachers also completed the Behavior Rating Inventory of Executive Function-Preschool Version (BRIEF-P; Gioia et al. 1996) or Child Version (BRIEF-2; Gioia et al. 2000) for 
participating children. The BRIEF-P is a standardized 63-item questionnaire that measures various aspects of executive functioning in children aged 2-5 years and 11 months. The BRIEF-2 is a standardized 63-item questionnaire that measures various aspects of executive functioning in children aged 5-18. Both the BRIEF-P and BRIEF-2 required teachers to rate children's behaviors on a three-point scale $(0=$ never, $1=$ sometimes, $2=$ often $)$. The Global Executive Composite (GEC; Cronbach's $\alpha$ for Preschool and Child versions was 0.98 and 0.97 , respectively) was used from both versions of the BRIEF for this study. The GEC is intended to provide a measure of a child's overall executive function, which takes into account all of the clinical scales (i.e., Initiate, Working Memory, Plan/Organize, Monitor, Shift, and Emotional Control). Higher GEC score indicates deficits in one or more areas of executive function. Both the BASC- 3 and the BRIEF measures are used widely in clinical and research applications and have strong psychometric properties.

\section{Data Analyses}

Means and standard deviations (SD) for continuous variables, and absolute and relative frequencies for categorical variables were reported. Chi-Square test for categorical covariates and independent $t$ test for continuous covariates were used to compare the two study groups at baseline (Table 2). In addition, the five study outcomes (i.e., BSI, internalizing composite, externalizing composite, adaptive skills, and GEC) were compared between the two study groups using independent $t$ test, and their change scores over one-time follow-up were examined using paired $t$ test (Table 3 ). The study outcomes were fitted using multilevel linear regression models to account for clustering with three levels: (a) time-specific observations (i.e., two time points), (b) students, and (c) classes. The likelihood ratio (LR) test supported an improvement in the variances favoring a three-level model (e.g., LR Chisquare $=607.0 ; P$ value $<0.001$ for BSI scale). In the third level, intra-class correlations (ICC) were reported to show the proportion of the variation in the study outcomes attributable to the clustering of the study classes. For each study outcome, two models were constructed to explore the impact of the intervention (Tables 4, 5, and 6). In model 1, we examined the impact of the intervention considering the clustering levels, with time and its interaction term included in the model to demonstrate the change over time among students who were exposed to the intervention versus students in the comparison group (i.e., unadjusted model). To account for the imbalanced distribution of the student- and class-level covariates at baseline, in model 2, we examined the impact of the MindUP intervention adjusting for age, class SRI, and class size (i.e., adjusted model). The interaction of the study group and time provides the difference-in-difference estimations, referring to the difference in the average change over time in the study outcomes for the intervention group and the average change over time for the comparison group. The negative coefficients indicate the improvement of the outcome over

Table 2 Descriptive characteristics of the study participants $(N=584)$

\begin{tabular}{|c|c|c|c|c|}
\hline \multirow[t]{2}{*}{ Variables } & \multirow[t]{2}{*}{ Entire sample } & \multicolumn{2}{|l|}{ Study groups } & \multirow[b]{2}{*}{$P$ value } \\
\hline & & Comparison group & Intervention group & \\
\hline$N$ & $584(100.0)^{\mathrm{a}}$ & $323(55.31)$ & $261(44.69)$ & --- \\
\hline \multicolumn{5}{|l|}{ Student-level characteristics } \\
\hline Gender & & & & $0.806^{\mathrm{b}}$ \\
\hline Boys & $283(48.46)$ & $158(48.92)$ & $125(47.89)$ & \\
\hline Girls & $301(51.54)$ & $165(51.08)$ & $136(52.11)$ & \\
\hline Age at time 1 (years), mean [SD] & $4.37[0.58]$ & $4.45[0.55]$ & $4.27[0.61]$ & $<0.001^{\mathrm{c}}$ \\
\hline Ethnicity & & & & $0.154^{\mathrm{b}}$ \\
\hline Non-White & $169(29.91)$ & $85(27.42)$ & $84(32.94)$ & \\
\hline White & $396(70.09)$ & $225(72.58)$ & $171(67.06)$ & \\
\hline \multicolumn{5}{|l|}{ Class-level characteristics } \\
\hline SRI category & & & & $<0.001^{\mathrm{b}}$ \\
\hline Low to moderate & $223(38.18)$ & $204(63.16)$ & $19(7.28)$ & \\
\hline Somewhat high or high & $361(61.82)$ & $119(36.84)$ & $242(92.72)$ & \\
\hline Class size, mean $[\mathrm{SD}]$ & $23.03[3.40]$ & $23.51[3.14]$ & $22.42[3.60]$ & $<0.001^{\mathrm{c}}$ \\
\hline Teachers' experience (years), mean [SD] & $17.44[10.33]$ & $17.77[9.61]$ & $17.02[11.15]$ & $0.392^{\mathrm{c}}$ \\
\hline
\end{tabular}


Table 3 T-score descriptive statistics of the study outcomes across the groups

\begin{tabular}{|c|c|c|c|}
\hline & Comparison group & Intervention group & Between-group $P$ value ${ }^{\mathrm{b}}$ \\
\hline \multicolumn{4}{|c|}{ Behavioral Symptom Index (BSI) } \\
\hline Pre-intervention & $46.71(9.50)^{\mathrm{a}}$ & $51.19(10.84)$ & $<0.001$ \\
\hline Post-intervention & $47.4(9.78)$ & $49.61(10.35)$ & 0.011 \\
\hline Within-group $p$ value ${ }^{\mathrm{c}}$ & 0.083 & $<0.001$ & \\
\hline \multicolumn{4}{|l|}{ Internalizing composite } \\
\hline Pre-intervention & $47.78(9.50)$ & $51.27(10.16)$ & $<0.001$ \\
\hline Post-intervention & $50.26(10.03)$ & $50.82(9.52)$ & 0.505 \\
\hline Within-group $p$ value ${ }^{c}$ & $<0.001$ & 0.371 & \\
\hline \multicolumn{4}{|l|}{ Externalizing composite } \\
\hline Pre-intervention & $45.77(8.23)$ & $49.71(10.80)$ & $<0.001$ \\
\hline Post-intervention & $46.74(8.73)$ & $48.91(10.09)$ & 0.008 \\
\hline Within-group $p$ value $\mathrm{e}^{\mathrm{c}}$ & 0.002 & 0.018 & \\
\hline \multicolumn{4}{|l|}{ Adaptive composite scale } \\
\hline Pre-intervention & $52.84(9.85)$ & $48.78(8.87)$ & $<0.001$ \\
\hline Post-intervention & $53.06(9.54)$ & $52.26(8.49)$ & 0.305 \\
\hline Within-group $p$ value ${ }^{c}$ & 0.384 & $<0.001$ & \\
\hline \multicolumn{4}{|c|}{ Global executive composite (GEC) } \\
\hline Pre-intervention & $51.58(13.07)$ & $57.7(13.81)$ & $<0.001$ \\
\hline Post-intervention & $50.54(12.22)$ & $52.29(12.30)$ & 0.097 \\
\hline Within-group $p$ value ${ }^{c}$ & 0.002 & $<0.001$ & \\
\hline
\end{tabular}

time in the intervention group vs. comparison group, and positive coefficients indicate the improvement of the outcome over time in the intervention group vs. comparison group. The interaction between intervention and gender was also assessed for each outcome; however, no gender-specific analysis was reported as no significant interactions were identified between gender and the intervention (data are not shown but available upon request). Unadjusted and adjusted beta $(\beta)$ coefficients, along with standard errors (SE) were reported for the fixed part of the models, and variances explained at each level was reported for the random part. Data were analyzed in SPSS v.24 (IBM) and Stata v.15 (StataCorp, College Station, Texas).

\section{Results}

\section{Intervention Implementation}

Of the 14 educators who submitted the lesson tracking sheets upon program completion, 13 (93\%) reported that they implemented all 15 lessons. The educators spent, on average, 43 min per lesson ( $S D$ 33.12), indicating high levels of implementation. The educators also demonstrated high program adherence by completing multiple curricular components for each lesson.

\section{Pre-implementation Characteristics}

The pre-intervention characteristics, both student- and classlevel characteristics of the entire sample and the intervention and comparison groups, are provided in Table 2. Slightly more than half of the overall sample were girls (51.54\%), with $51.08 \%$ and $52.11 \%$ in the comparison and intervention groups, respectively ( $P$ value $=0.806$ ). Mean $(\mathrm{SD})$ age of the entire sample was $4.37(0.58)$ years old, with $4.45(0.55)$ and $4.27(0.61)$ in the comparison and intervention groups, respectively $(P$ value $\leq 0.001)$. More than two-thirds of the entire sample reported being white $(70.09 \%)$, with $72.58 \%$ and $67.06 \%$ in the two study groups, respectively. Class-level characteristics included SRI, with around two-thirds (61.8\%) categorized as somewhat high or high, with $36.84 \%$ in the comparison groups versus $92.72 \%$ in the intervention group ( $P$ value $<0.001)$; class size, with an average $(\mathrm{SD})$ of 23.03 (3.40) students in each class, with 23.51 (3.14) in the comparison group and 22.42 (3.60) in the intervention group $(P$ value $<0.001$ ); and teachers' experience, with an average (SD) of 17.44 (10.33) years reported teaching experience in the entire 
Table 4 Multilevel models of the BASC-3 Behavioral Symptom Index (BSI) and BASC-3 Adaptive Composite Scale examining the effect of the intervention of interest, adjusting for student- and class-level covariates

\begin{tabular}{|c|c|c|c|c|c|c|c|c|}
\hline \multirow[b]{3}{*}{ Fixed part } & \multicolumn{4}{|c|}{ BASC-3 Behavioral Symptom Index (BSI) } & \multicolumn{4}{|c|}{ BASC-3 Adaptive Composite Scale } \\
\hline & \multicolumn{2}{|c|}{ Unadjusted model $^{\mathrm{a}}$} & \multicolumn{2}{|c|}{ Adjusted model $^{\mathrm{b}}$} & \multicolumn{2}{|c|}{ Unadjusted model $^{\mathrm{a}}$} & \multicolumn{2}{|c|}{ Adjusted model $^{\mathrm{b}}$} \\
\hline & Beta $(\mathrm{SE})^{\mathrm{f}}$ & $P$ value & Beta (SE) & $P$ value & Beta (SE) & $P$ value & Beta (SE) & $P$ value \\
\hline Intercept & $47.0(1.02)$ & $<0.001$ & $48.4(5.1)$ & $<0.001$ & $52.7(0.9)$ & $<0.001$ & $46.6(4.8)$ & $<0.001$ \\
\hline \multicolumn{9}{|l|}{ Study groups (at time 1) } \\
\hline Comparison & Ref & --- & Ref & --- & Ref & --- & Ref & --- \\
\hline Intervention & $4.51(1.5)$ & 0.002 & $5.73(1.8)$ & 0.001 & $-4.14(1.4)$ & 0.004 & $-3.75(1.8)$ & 0.034 \\
\hline Time in comparison group ${ }^{c}$ & $0.51(0.4)$ & 0.145 & $0.51(0.4)$ & 0.145 & $0.30(0.4)$ & 0.413 & $0.30(0.4)$ & 0.413 \\
\hline Intervention $\times$ time $^{\mathrm{d}}$ & $-2.47(0.5)$ & $<0.001$ & $-2.47(0.5)$ & $<0.001$ & $3.46(0.6)$ & $<0.001$ & $3.45(0.6)$ & $<0.001$ \\
\hline Random part & $\mathrm{SD}(\mathrm{SE})^{\mathrm{g}}$ & & $\mathrm{SD}(\mathrm{SE})$ & & $\mathrm{SD}(\mathrm{SE})$ & & $\mathrm{SD}(\mathrm{SE})$ & \\
\hline Level (class) & $3.82(0.5)$ & & $3.71(0.6)$ & & $3.79(0.6)$ & & $3.84(0.6)$ & \\
\hline Level (children) & $8.05(0.3)$ & & $8.04(0.3)$ & & $7.00(0.3)$ & & $6.84(0.3)$ & \\
\hline Level (time) & $4.38(0.1)$ & & $4.38(0.1)$ & & $4.56(0.1)$ & & $4.56(0.1)$ & \\
\hline ICC class, \% (SE) ${ }^{\mathrm{e}}$ & $14.8 \%(0.04)$ & & $14.1 \%(0.04)$ & & $17.1 \%(0.04)$ & & $17.8 \%(0.04)$ & \\
\hline
\end{tabular}

${ }^{a}$ Random-intercept model, including intervention and time variables, and their interaction

${ }^{\mathrm{b}}$ Adjusted for age, class SRI, and class size

${ }^{\mathrm{c}}$ Referring to the change score over time in the outcomes (BSI and adaptive composite) in the comparison group

${ }^{\mathrm{d}}$ These interaction terms (italicized estimates) imply the difference-in-difference estimation: referring to the difference in the average change over time in the outcomes for the intervention group and the average change over time for the comparison group, with negative coefficients in BSI indicating the improvement of this outcome over time in the intervention group vs. comparison group, and positive coefficients in adaptive composite indicating the improvement of this outcome over time in the intervention group vs. comparison group

e ICC: Intra-class correlation, referring to the percentage of the variations in BSI being explained by clusters (classes)

${ }^{\mathrm{f}}$ Beta coefficient (standard error)

${ }^{\mathrm{g}}$ Standard deviation (standard error), unless otherwise specified

sample, with 17.77 (9.61) and 17.02 (11.15) in the comparison and intervention groups, respectively $(P$ value $=0.392)$.

Results comparing the study outcomes across the study groups at pre-intervention showed that comparison group had a lower mean $(\mathrm{SD})$ value relative to the intervention groups with regard to (a) BSI scale (46.71 (9.50) vs. 51.19 (10.84), respectively, $P$ value $<0.001$ ), (b) internalizing composite $(47.78(9.50)$ vs. $51.27(10.16), P$ value $<0.001)$, (c) externalizing composite $(45.77$ (8.23) vs. 49.71 (10.80), $P$ value $<0.001)$, and (d) GEC scale (51.58 (13.07) vs. 57.7 (13.81), $P$ value $<0.001)$. Conversely, the comparison group had a higher mean (SD) value for adaptive skills relative to the intervention group (52.84 (9.85) vs. 48.78 (8.87), $P$ value $<$ 0.001 ). Detailed between-group comparisons at both pre- and post-intervention time periods, as well as within-group comparisons, are shown in Table 3.

\section{Impact of the Intervention on BSI and Adaptive Skills}

Unadjusted and adjusted models showed that the intervention reduced BSI T-score among students in the intervention relative to the comparison group. Controlling for student- and class-level covariates, adjusted models demonstrated that
BSI T-score was significantly reduced, on average, 2.23 units among students in the intervention in contrast to the reductions in the comparison group over time (i.e., adjusted $\beta=-$ $2.47(\mathrm{SE}=0.5), P$ value $<0.001)$. As seen in Table 4 , the adjusted model showed that adaptive skills T-score was significantly increased by, on average, 3.45 units among students in the intervention group versus those in the comparison group (i.e., adjusted $\beta=3.45(\mathrm{SE}=0.6), P$ value $<0.001)$.

\section{Impact of the Intervention on Internalizing and Externalizing Behaviors}

The adjusted models showed that the intervention reduced the BASC-3 internalizing composite among students in the intervention group compared to those in the comparison group (i.e., adjusted $\beta=-2.73$ ( $\mathrm{SE}=0.7), P$ value $<0.001)$. In terms of the externalizing composite, a similar pattern emerged such that those in the intervention group had a higher reduction in externalizing behaviors than those in the comparison groups (i.e., adjusted $\beta=-2.05(\mathrm{SE}=0.5), P$ value $<0.001)$. See Table 5. 
Table 5 Multilevel models of the BASC-3 Internalizing Composite and Externalizing Composite examining the effect of the intervention of interest, adjusting for student- and class-level covariates

\begin{tabular}{|c|c|c|c|c|c|c|c|c|}
\hline \multirow[b]{3}{*}{ Fixed part } & \multicolumn{4}{|c|}{ Internalizing composite } & \multicolumn{4}{|c|}{ Externalizing composite } \\
\hline & \multicolumn{2}{|c|}{ Unadjusted model $^{\mathrm{a}}$} & \multicolumn{2}{|c|}{ Adjusted model $^{\mathrm{b}}$} & \multicolumn{2}{|c|}{ Unadjusted model $^{\mathrm{a}}$} & \multicolumn{2}{|c|}{ Adjusted model $^{\mathrm{b}}$} \\
\hline & Beta $(\mathrm{SE})^{\mathrm{f}}$ & $P$ value & Beta (SE) & $P$ value & Beta (SE) & $P$ value & Beta (SE) & $P$ value \\
\hline Intercept & $48.1(1.2)$ & $<0.001$ & $39.1(5.5)$ & $<0.001$ & $45.9(0.8)$ & $<0.001$ & $46.2(4.4)$ & $<0.001$ \\
\hline \multicolumn{9}{|l|}{ Study groups (at time 1) } \\
\hline Comparison & Ref & --- & Ref & --- & Ref & --- & Ref & --- \\
\hline Intervention & $2.70(1.8)$ & 0.126 & $4.14(2.2)$ & 0.059 & $4.19(1.2)$ & $<0.001$ & $5.25(1.4)$ & $<0.001$ \\
\hline Time in comparison group ${ }^{c}$ & $2.21(0.4)$ & $<0.001$ & $2.20(0.4)$ & $<0.001$ & $0.91(0.3)$ & 0.008 & $0.91(0.3)$ & 0.008 \\
\hline Intervention $\times$ time $^{\mathrm{d}}$ & $-2.73(0.7)$ & $<0.001$ & $-2.73(0.7)$ & $<0.001$ & $-2.05(0.5)$ & $<0.001$ & $-2.05(0.5)$ & $<0.001$ \\
\hline Random part & $\mathrm{SD}(\mathrm{SE})^{\mathrm{g}}$ & & $\mathrm{SD}(\mathrm{SE})$ & & $\mathrm{SD}(\mathrm{SE})$ & & $\mathrm{SD}(\mathrm{SE})$ & \\
\hline Level (class) & $5.04(0.7)$ & & $5.03(0.7)$ & & $2.83(0.5)$ & & $2.61(0.5)$ & \\
\hline Level (children) & $6.25(0.3)$ & & $6.16(0.3)$ & & $7.73(0.3)$ & & $7.72(0.3)$ & \\
\hline Level (time) & $5.53(0.2)$ & & $5.53(0.2)$ & & $4.2(0.1)$ & & $4.25(0.1)$ & \\
\hline ICC class, \% (SE) ${ }^{\mathrm{e}}$ & $26.7 \%(0.05)$ & & $26.9 \%(0.05)$ & & $9.3 \%(0.03)$ & & $8.1 \%(0.03)$ & \\
\hline
\end{tabular}

${ }^{a}$ Random-intercept model, including intervention and time variables, and their interaction

${ }^{\mathrm{b}}$ Adjusted for age, class SRI, and class size

${ }^{\mathrm{c}}$ Referring to the change score over time in the outcomes (internalizing and externalizing composites) in the comparison group

${ }^{\mathrm{d}}$ These interaction terms (italicized estimates) imply the difference-in-difference estimation: referring to the difference in the average change over time in the outcomes for the intervention group and the average change over time for the comparison group, with negative coefficients indicating the improvement of the outcomes over time in the intervention group compared to comparison group

${ }^{\mathrm{e}} \mathrm{ICC}$ : intra-class correlation, referring to the percentage of the variations in the outcomes being explained by clusters (classes)

${ }^{\mathrm{f}}$ Beta coefficient (standard error)

${ }^{\mathrm{g}}$ Standard deviation (standard error), unless otherwise specified

\section{Impact of the Intervention on GEC}

The adjusted model showed that GEC T-scores were significantly reduced, on average, 4.51 units among students in the intervention group in comparison to the reductions in the comparison group over time (i.e., adjusted $\beta=-4.51(\mathrm{SE}=0.7), P$ value $<0.001$ ). See table 6 .

\section{Discussion}

This research contributes to the scant literature on the impacts of mindfulness-based SEL programs on young children. Our design addressed some of the concerns with previous studies by including a larger sample size and a sufficient number of clusters (i.e., classrooms) to account for the natural grouping of children. Overall, we saw significant gains for children in all areas that we measured, including reduction of behavioral symptoms, reduction of internalizing and externalizing behavior problems, increase in adaptive skills, and reduction of executive functioning deficits. Interestingly, for adaptive skills and executive functioning, both groups improved significantly (see Table 3 for within-group differences), with the intervention group improving much more rapidly. However, in the case of internalizing problems, the intervention group improved and the comparison group actually worsened over the course of the school year.

Among the areas we evaluated, MindUP had the strongest impacts on reducing executive functioning deficits. These improvements in executive functioning are consistent with previous research on MindUP with older students (SchonertReichl et al. 2015) and preschool-aged students (Thierry et al. 2016; Thierry et al. 2018). Other researchers have postulated that mindfulness programs help young children practice and develop their attentional flexibility, inhibitory control, and effective emotional regulation, which in turn are reflected in better improved executive functionings (Kim et al. 2020).

\section{Limitations and Future Research}

Despite the promising results on the effects of mindfulnessbased SEL intervention on children, the study has several limitations. Although the current design had comparison classrooms, schools were not randomized into the two conditions. Our school board partner does not endorse randomization because they need to take other considerations into account in making programming decisions. As a result, the intervention group had much higher social risk indicators and 
Table 6 Multilevel models of the BRIEF-2 Global Executive Composite (GEC) examining the effect of the intervention of interest, adjusting for student- and class-level covariates

\begin{tabular}{|c|c|c|c|c|}
\hline \multirow[b]{2}{*}{ Fixed part } & \multicolumn{2}{|c|}{ Unadjusted model $^{\mathrm{a}}$} & \multicolumn{2}{|c|}{ Adjusted model $^{\mathrm{b}}$} \\
\hline & Beta $(\mathrm{SE})^{\mathrm{f}}$ & $P$ value & Beta (SE) & $P$ value \\
\hline Intercept & $51.9(1.3)$ & $<0.001$ & $59.8(6.6)$ & $<0.001$ \\
\hline \multicolumn{5}{|l|}{ Study groups (at time 1) } \\
\hline Comparison & Ref & --- & Ref & --- \\
\hline Intervention & $6.23(1.9)$ & 0.001 & $7.19(2.3)$ & 0.002 \\
\hline Time in comparison group ${ }^{c}$ & $-1.23(0.5)$ & 0.010 & $-1.23(0.5)$ & 0.010 \\
\hline Intervention $\times$ time $^{\mathrm{d}}$ & $-4.51(0.7)$ & $<0.001$ & $-4.51(0.7)$ & $<0.001$ \\
\hline \multicolumn{5}{|l|}{ Random part } \\
\hline Level (class) & $4.95(0.7)$ & & $4.92(0.7)$ & \\
\hline Level (children) & $10.14(0.4)$ & & $10.03(0.4)$ & \\
\hline Level (time) & $5.98(0.2)$ & & $5.98(0.2)$ & \\
\hline ICC class, $\%(\mathrm{SE})^{\mathrm{e}}$ & $15.0 \%(0.04)$ & & $15.1 \%(0.04)$ & \\
\hline
\end{tabular}

${ }^{a}$ Random-intercept model, including intervention and time variables, and their interaction

${ }^{\mathrm{b}}$ Adjusted for age, class SRI, and class size

${ }^{\mathrm{c}}$ Referring to the change score over time in GEC in the comparison group

${ }^{\mathrm{d}}$ These interaction terms (italicized estimates) imply the difference-in-difference estimation: referring to the difference in the average change over time in GEC for the intervention group and the average change over time for the comparison group, with negative coefficients indicating the improvement of GEC over time in the intervention group compared to comparison group

${ }^{\mathrm{e}}$ ICC: intra-class correlation, referring to the percentage of the variations in GEC being explained by clusters (classes)

${ }^{\mathrm{f}}$ Beta coefficient (standard error)

${ }^{\mathrm{g}}$ Standard deviation (standard error), unless otherwise specified higher levels of behavioral challenges pre-intervention versus children in comparison schools. Although we controlled for classroom level covariates that differed between the two conditions, this adjustment is not optimal compared to groups that start out more equitably. In addition, teachers were aware of the children's treatment condition and had a dual role of being both implementers and raters. As a result, their responses may have been influenced by expectancy effect. Adding parent ratings would be another option, but because behavior is so context-dependent, it might not be realistic to expect changes in behavior at home without specific efforts to support the generalization of gains. Furthermore, although educators implementing MindUP would experience a potential bias, the comparison educators are also utilizing classroom strategies that they feel are effective and would likely experience a similar bias of wanting the students in their class to show better self-regulation as the year progresses. Adding selfreport measures can provide another perspective, but it is not feasible with children as young as the ones in this study.

Another limitation was obtaining incomplete fidelity data that relied on self-report. Thus, while we can report the amount of time teachers spent on the program as a group, we did not have sufficient data to use dosage as a covariate. When the program is implemented well, it extends beyond the individual lessons to include daily practice integrated into other activities. This limitation has been highlighted in the field of school-based mindfulness interventions, and there is a need to better identify and measure core components to assess fidelity (Feagans Gould et al. 2016). Future research should evaluate the quality of implementation through classroom observation of teachers' lesson delivery when feasible. Finally, we anticipate that there was some contamination of the comparison group with mindfulness-based activities and yoga due to the general rise in popularity of these approaches. We did not document any comparable activities in either condition.

In summary, our findings contribute to the existing scientific literature by demonstrating the benefits of a mindfulnessbased SEL intervention on positive and negative indicators of well-being in young children. Behavioral symptoms, internalizing and externalizing problems, and adaptive skills improved for kindergarten students exposed to the intervention. Consistent with previous literature, the largest improvement was found for executive functioning, regardless of gender. Examining the components of executive functioning specifically, and its role in self-regulation are important to be considered in future research. Furthermore, adding performancebased measures of executive functioning, or ratings from other informants could strengthen the findings reported in this paper. Focusing on the development of executive functioning is 
a high priority, because fostering these skills in early years is critical to mental health and well-being across the lifespan.

Acknowledgments We would like to acknowledge Terry Spencer, Research and Evaluation Officer, and Sandra Savage, Mental Health Lead, with the London District Catholic School Board for their contributions to the implementation of MindUP and this research. Their leadership and commitment are inspiring. We are also grateful for the educators who implemented the intervention and control conditions and participated in the research.

Funding Information This research was funded by a grant from the Public Health Agency of Canada to the first author.

Open Access This article is licensed under a Creative Commons Attribution 4.0 International License, which permits use, sharing, adaptation, distribution and reproduction in any medium or format, as long as you give appropriate credit to the original author(s) and the source, provide a link to the Creative Commons licence, and indicate if changes were made. The images or other third party material in this article are included in the article's Creative Commons licence, unless indicated otherwise in a credit line to the material. If material is not included in the article's Creative Commons licence and your intended use is not permitted by statutory regulation or exceeds the permitted use, you will need to obtain permission directly from the copyright holder. To view a copy of this licence, visit http://creativecommons.org/licenses/by/4.0/.

\section{References}

Bonell, C. P., Hargreaves, J., Cousens, S., Ross, D., Hayes, R., Petticrew, M., \& Kirkwood, B. R. (2011). Alternatives to randomisation in the evaluation of public health interventions: design challenges and solutions. Journal of Epidemiology \& Community Health, 65(7), 582587. https://doi.org/10.1136/jech.2008.082602.

de Carvalho, J. S., Pinto, A. M., \& Mar co, J. (2017). Results of a mindfulness-based social-emotional learning program on Portuguese elementary students and teachers: a quasi-experimental study. Mindfulness, 8(2), 337-350. https://doi.org/10.1007/s12671016-0603-z.

Domitrovich, C. E., Durlak, J. A., Staley, K. C., \& Weissberg, R. P. (2017). Social-emotional competence: an essential factor for promoting positive adjustment and reducing risk in school children. Child Development, 88(2), 408-416. https://doi.org/10.1111/cdev. 12739.

Durlak, J. A., Weissberg, R. P., Dymnicki, A. B., Taylor, R. D., \& Schellinger, K. B. (2011). The impact of enhancing students' social and emotional learning: a meta-analysis of school-based universal interventions. Child Development, 82(1), 405-432. https://doi.org/ 10.1111/j.1467-8624.2010.01564.x.

Feagans Gould, L., Dariotis, J. K., Greenberg, M. T., \& Mendelson, T. (2016). Assessing fidelity of implementation (FOI) for school-based mindfulness and yoga interventions: a systematic review. Mindfulness, 7(1), 5-33. https://doi.org/10.1007/s12671-015-03956.

Felver, J. C., Celis-de Hoyos, C. E., Tezanos, K., \& Singh, N. N. (2016). A systematic review of mindfulness-based interventions for youth in school settings. Mindfulness, 7(1), 34-45. https://doi.org/10.1007/ s12671-015-0389-4.

Feuerborn, L. L., \& Gueldner, B. (2019). Mindfulness and socialemotional competencies: proposing connections through a review of the research. Mindfulness, 10(9), 1707-1720. https://doi.org/10. 1007/s12671-019-01101-1.
Gioia, G. A., Andrews, K., \& Isquith, P. K. (1996). Behavior rating inventory of executive function-preschool version (BRIEF-P). Psychological Assessment Resources.

Gioia, G. A., Isquith, P. K., Guy, S. C., \& Kenworthy, L. (2000). BRIEF: behavior rating inventory of executive function. Psychological Assessment Resources.

Greenberg, M. T., Weissberg, R. P., O'Brien, M. U., Zins, J. E., Fredericks, L., Resnik, H., \& Elias, M. J. (2003). Enhancing school-based prevention and youth development through coordinated social, emotional, and academic learning. American Psychologist, 58(6-7), 466-474. https://doi.org/10.1037/0003066X.58.6-7.466.

Greenberg, M. T., Domitrovich, C. E., Weissberg, R. P., \& Durlak, J. A. (2017). Social and emotional learning as a public health approach to education. The Future of Children, 13-32. https://doi.org/10.1353/ foc. 2017.0001

Kim, E., Jackman, M. M., Jo, S., Oh, J., Ko, S., McPherson, C. L., Hwang, Y., \& Singh, N. N. (2020). Effectiveness of the mindfulness-based OpenMind-Korea (OM-K) preschool program. Mindfulness, 11(4), 1062-1072. https://doi.org/10.1007/s12671020-01337-2.

La Paro, K. M., Rimm-Kaufman, S. E., \& Pianta, R. C. (2006). Kindergarten to 1 st grade: classroom characteristics and the stability and change of children's classroom experiences. Journal of Research in Childhood Education, 21(2), 189-202. https://doi.org/ $10.1080 / 02568540609594588$.

Maguire, L. K., Niens, U., McCann, M., \& Connolly, P. (2016). Emotional development among early school-age children: gender differences in the role of problem behaviours. Educational Psychology, 36(8), 1408-1428. https://doi.org/10.1080/01443410. 2015.1034090

Maloney, J. E., Lawlor, M. S., Schonert-Reichl, K. A., \& Whitehead, J. (2016). A mindfulness-based social and emotional learning curriculum for school-aged children: the MindUP program. In K. A. Schonert-Reichl \& R. W. Roeser (Eds.), Mindfulness in behavioral health: Handbook of mindfulness in education: integrating theory and research into practice (pp. 313-334). Springer. https://doi.org/ 10.1007/978-1-4939-3506-2_20.

Maynard, B. R., Solis, M. R., Miller, V. L., \& Brendel, K. E. (2017). Mindfulness-based interventions for improving cognition, academic achievement, behavior, and socio-emotional functioning of primary and secondary school students. Campbell Systematic Reviews, 13(5), 1-147. https://doi.org/10.4073/csr2017.5.

McClelland, M. M., Acock, A. C., Piccinin, A., Rhea, S. A., \& Stallings, M. C. (2013). Relations between preschool attention spanpersistence and age 25 educational outcomes. Early Childhood Research Quarterly, 28, 314-324. https://doi.org/10.1016/j.ecresq. 2012.07.008.

Montroy, J. J., Bowles, R. P., Skibbe, L. E., McClelland, M. M., \& Morrison, F. J. (2016). The development of self-regulation across early childhood. Developmental Psychology, 52(11), 1744-1762. https://doi.org/10.1037/dev0000159.

Moreno-Gómez, A., \& Cejudo, J. (2019). Effectiveness of a mindfulnessbased social-emotional learning program on psychosocial adjustment and neuropsychological maturity in kindergarten children. Mindfulness, 10(1), 111-121. https://doi.org/10.1007/s12671-0180956-6.

Napoli, M., Krech, P. R., \& Holley, L. C. (2005). Mindfulness training for elementary school students: the attention academy. Journal of Applied School Psychology, 21(1), 99-125. https://doi.org/10. 1300/J370v21n01 05.

Oberle, E., Domitrovich, C. E., Meyers, D. C., \& Weissberg, R. P. (2016). Establishing systemic social and emotional learning approaches in schools: a framework for school wide implementation. Cambridge Journal of Education, 46(3), 277-297. https://doi.org/ 10.1080/0305764X.2015.1125450. 
Reynolds, C. R., \& Kamphaus, R. W. (2015). Behavior assessment system for children-third edition (BASC-3). Pearson.

Schonert-Reichl, K. A., \& Lawlor, M. S. (2010). The effects of mindfulness-based education program on pre- and early adolescents' well-being and social and emotional competence. Mindfulness, 1(3), 137-151. https://doi.org/10.1007/s12671-0100011-8.

Schonert-Reichl, K. A., Oberle, E., Lawlor, M. S., Abbott, D., Thomson, K., Oberlander, T. F., \& Diamond, A. (2015). Enhancing cognitive and social-emotional development through a simple-to-administer mindfulness-based school program for elementary school children: a randomized controlled trial. Developmental Psychology, 51(1), 52-66. https://doi.org/10.1037/a0038454.

Semple, R. J., Droutman, V., \& Reid, B. A. (2017). Mindfulness goes to school: things learned (so far) from research and real-world experiences. Psychology in the Schools, 54(1), 29-52. https://doi.org/10. 1002/pits.21981.

Sklad, M., Diekstra, R., Ritter, M. D., Ben, J., \& Gravesteijn, C. (2012). Effectiveness of school-based universal social, emotional, and behavioral programs: do they enhance students' development in the area of skill, behavior, and adjustment? Psychology in the Schools, 49(9), 892-909. https://doi.org/10.1002/pits.21641.

Tang, Y., Holzel, B. K., \& Posner, M. I. (2015). The neuroscience of mindfulness meditation. Nature Reviews Neuroscience, 16(4), 213 225. https://doi.org/10.1038/nrn3916.
Taylor, R. D., Oberle, E., Durlak, J. A., \& Weissberg, R. P. (2017). Promoting positive youth development through school-based social and emotional learning interventions: a meta-analysis of follow-up effects. Child Development, 88(4), 1156-1171. https://doi.org/10. 1111/cdev.12864.

Thierry, K. L., Bryant, H. L., Nobles, S. S., \& Norris, K. S. (2016). Twoyear impact of a mindfulness-based program on pre-schoolers' selfregulation and academic performance. Early Education and Development, 27(6), 805-821. https://doi.org/10.1080/10409289. 2016.1141616.

Thierry, K. L., Vincent, R. L., Bryant, H. L., Kinder, B. K., \& Wise, C. L. (2018). A self-oriented mindfulness-based curriculum improves prekindergarten students' executive functions. Mindfulness, 9(5), 1443-1456. https://doi.org/10.1007/s12671-018-0888-1.

Zenner, C., Herrnleben-Kurz, S., \& Walach, H. (2014). Mindfulnessbased interventions in schools - a systematic review and meta-analysis. Frontiers in Psychology, 5, 603. https://doi.org/10.3389/fpsyg. 2014.00603.

Publisher's Note Springer Nature remains neutral with regard to jurisdictional claims in published maps and institutional affiliations. 